\title{
Impact Total Psoas Volume on Short- and Long-Term Outcomes in Patients Undergoing Curative Resection for Pancreatic Adenocarcinoma: a New Tool to Assess Sarcopenia
}

\author{
Neda Amini ${ }^{1}$, Gaya Spolverato ${ }^{1}$, Rohan Gupta ${ }^{1}$, Georgios A. Margonis ${ }^{1}$, Yuhree Kim ${ }^{1}$, Doris \\ Wagner $^{1}$, Neda Rezaee ${ }^{1}$, Matthew J. Weiss ${ }^{1}$, Christopher L. Wolfgang ${ }^{1}$, Martin M. Makary ${ }^{1}$, \\ Ihab R. Kamel ${ }^{2}$, and Timothy M. Pawlik ${ }^{1}$ \\ ${ }^{1}$ Department of Surgery, The Johns Hopkins University School of Medicine, 600 N. Wolfe Street, \\ Blalock 688, Baltimore, MD 21287, USA \\ ${ }^{2}$ Department of Radiology, The Johns Hopkins University School of Medicine, Baltimore, MD, \\ USA
}

\begin{abstract}
Background-While sarcopenia is typically defined using total psoas area (TPA), characterizing sarcopenia using only a single axial cross-sectional image may be inadequate. We sought to evaluate total psoas volume (TPV) as a new tool to define sarcopenia and compare patient outcomes relative to TPA and TPV.
\end{abstract}

\begin{abstract}
Method-Sarcopenia was assessed in 763 patients who underwent pancreatectomy for pancreatic adenocarcinoma between 1996 and 2014. It was defined as the TPA and TPV in the lowest sexspecific quartile. The impact of sarcopenia defined by TPA and TPV on overall morbidity and mortality was assessed using multivariable analysis.
\end{abstract}

\begin{abstract}
Result-Median TPA and TPV were both lower in women versus men (both $P<0.001$ ). TPA identified $192(25.1 \%)$ patients as sarcopenic, while TPV identified 152 patients (19.9\%). Three hundred sixty-nine (48.4\%) patients experienced a postoperative complication. While TPAsarcopenia was not associated with higher risk of postoperative complications (OR 1.06; $P=0.72$ ), sarcopenia defined by TPV was associated with morbidity (OR 1.79; $P=0.002$ ). On multivariable analysis, TPV-sarcopenia remained independently associated with an increased risk of postoperative complications (OR 1.69; $P=0.006$ ), as well as long-term survival (HR 1.46; $P=0.006)$.
\end{abstract}

Conclusion-The use of TPV to define sarcopenia was associated with both short- and longterm outcomes following resection of pancreatic cancer. Assessment of the entire volume of the psoas muscle (TPV) may be a better means to define sarcopenia rather than a single axial image.

\section{Keywords}

Sarcopenia; Outcomes; Pancreas surgery; Morbidity; Mortality 


\section{Introduction}

Pancreatic cancer is the fifth most common cancer worldwide with 30,000 new cases diagnosed annually. ${ }^{1}$ Surgical resection is the only curative treatment option for pancreatic cancer patients with a 5-year survival of 20-25\%.,3 While the mortality associated with pancreatic resection has dramatically decreased over the last several decades, morbidity remains a problem. ${ }^{4-6}$ Specifically, up to $20-40 \%$ of patients will experience some type of complication following pancreatic resection. Perioperative complications not only affect patient quality of life, but can delay subsequent therapy and adversely impact long-term survival. ${ }^{7-10}$ Preoperative assessment of patients at risk for postoperative complications is therefore critical. Accurate identification of patients at high risk of perioperative morbidity can guide patient-physician discussions prior to surgery, as well as identify appropriate patients for "pre-habiliation." 11 Several studies have demonstrated that active alcoholism, coagulopathy, jaundice, acute renal failure, heart disease, and obesity are associated with increased postoperative morbidity and mortality after pancreatic resection. ${ }^{12-14}$ More recently, there has been interest in identifying more general parameters of "health" to risk stratify patients.

Frailty, defined as decreased physiologic reservoir, has been proposed as a more global metric of the patient's health status. ${ }^{15,16}$ In fact, 7 to $12 \%$ of individuals in the USA suffer from frailty, with women being at greater risk than men. ${ }^{17,18}$ Frailty can be evaluated using different techniques including the use of questionnaires/indices, as well as the assessment of hand grip strength, walking speed, and sitting time. ${ }^{19-21}$ These measures can, however, be cumbersome to obtain, as well as vary on a daily or weekly basis. ${ }^{22,23}$ Another key component of frailty is the loss of lean muscle mass or sarcopenia. ${ }^{24}$ Sarcopenia can occur in a wide range of body compositions including normal weight, overweight, and obese patients. In turn, sarcopenia is distinct from cancer-related weight loss or cachexia. ${ }^{25,26}$ Several emerging studies have suggested that sarcopenia may be associated with poor prognosis in cancer patients..$^{27,28}$

Sarcopenia has traditionally been defined using only a single axial cross-sectional image of the psoas muscle at the level of L3. ${ }^{29,30}$ Using this technique, sarcopenia is defined as the total psoas area (TPA), with sarcopenic patients having a smaller TPA. ${ }^{31,32}$ Defining sarcopenia only using a single axial cross-sectional image, however, may be inadequate. Recent advances in imaging have made volumetric — rather than cross-sectional area-the preferred method of diagnostic assessment in many clinical settings. ${ }^{33,34}$ Three-dimensional volumetric assessment of the psoas (i.e., total psoas volume (TPV)) has not been well studied or accepted as a means to define sarcopenia. As such, the objective of the current study was to evaluate the impact of sarcopenia on outcomes following curative resection of pancreatic cancer. More specifically, we sought to evaluate TPVas a new tool to define sarcopenia and compare patient outcomes relative to TPA and TPV. 


\section{Method}

\section{Study Design}

All patients who underwent curative intent resection for pancreatic adenocarcinoma at the Department of Surgery of the Johns Hopkins Hospital between April 1996 and March 2014 were identified. Perioperative abdominal computed tomography (CT) images (i.e., within 30 days before surgery) were available for re-review for 763 patients; these patients represented the study cohort. Standard demographic and clinicopathologic data were collected including data on age, sex, race, body mass index (BMI), tumor characteristics (stage, size, and grade), lymph node metastasis, lymphovascular invasion (LVI), perivascular invasion (PVI), operative details, and length of hospital stay. Data on perioperative morbidity and mortality were also collected. Postoperative complications were scored based on Clavien-Dindo classification with major complications being defined as Clavien grade $\geq 3 .{ }^{35}$ This study was approved by the Johns Hopkins Institutional Review Board.

\section{Image Analysis}

Using the Ultravisual software package (Merge Emageon, Birmingham, AL, USA), sarcopenia was initially assessed by measuring TPA at the level of L3 where both iliac crests were clearly visible. As previously described, measurements were performed in a semiautomated fashion with manual outlining of the psoas muscle borders. ${ }^{36} \mathrm{TPV}$ was assessed using AW Workstation Volume Viewer Software (GE Healthcare, Little Chalfont, United Kingdom). Specifically, TPV was calculated using three manual measurements at the level of L3 on the first slice where both iliac crests were visible by hand tracing the borders of the entire psoas muscle (Fig. 1). Three manual measurements of the psoas muscle were performed to assess a total of $55 \mathrm{~cm}$ total psoas length. All measurements were done in a semi-automated fashion with the density threshold setting between -30 and 110 Hounsfield Units (HU) to exclude vasculature and fatty infiltration areas from the volumetric calculations. Both TPV and TPA were normalized for height.

\section{Statistical Analysis}

Continuous variables were provided as median values with interquartile range (IQR).

Categorical variables were reported as totals and frequencies. The impact of sarcopenia was evaluated both as a continuous and a categorical variable. As previously reported and validated, to obtain specific sex categorical cutoff value for sarcopenia, optimum stratification was assessed through a series of sensitivity analyses and sarcopenia was defined in categorical analyses as the lowest quartile for men and women separately. ${ }^{26,30}$ The TPA cutoff to define sarcopenia was 414.5 and $564.2 \mathrm{~mm}^{2} / \mathrm{m}^{2}$ for women and men, respectively; the cutoff for TPV was $12.0 \mathrm{~cm}^{3} / \mathrm{m}^{2}$ for women and $17.2 \mathrm{~cm}^{3} / \mathrm{m}^{2}$ for men. The impact of sarcopenia on morbidity was assessed using univariable and multivariable logistic regression analyses. Overall survival was analyzed using the Kaplan-Meier method, and differences in survival were evaluated with the log-rank test. To identify prognostic factors after surgical intervention, variables significant on univariable analysis were included in the multivariable Cox proportional hazards model. Results were reported as odds ratios (OR) or hazard ratios (HR), where appropriate, with $95 \%$ confidence intervals $(95 \% \mathrm{CI})$. A $P$ value 
of $<0.05$ was considered statistically significant. All statistical analysis was carried out using statistical software package, Stata 12.0 (Stata Corp, College Station, TX, USA).

\section{Results}

\section{Demographics and Clinical Characteristics}

The baseline clinicopathologic characteristics of 763 patients who met study inclusion criteria were summarized in Table 1. Median patient age was 67.0 years (IQR 58, 74) and $54.8 \%(n=418)$ were males; most patients were Caucasian $(n=646,84.7 \%)$. Median pancreatic tumor size was $3.0 \mathrm{~cm}$ (IQR 2.3,4), and lymph node metastasis was common $(n=532,70.0 \%)$. According to the $7^{\text {th }}$ edition American Join Committee on Cancer (AJCC) staging system, ${ }^{37}$ the majority of tumors were stage II $(81.5 \%)$. Vascular and perineural invasion were present in $56.0 \%(n=367)$ and $86.5 \%(n=646)$ of patients, respectively. At the time of surgery, the operative procedure consisted of pancreatoduodenectomy ( $n=583$, $77.2 \%)$, distal pancreatectomy ( $n=139,18.4 \%)$, and total pancreatectomy $(n=33,4.4 \%)$.

The median TPA and TPV were $600.6 \mathrm{~mm}^{2} / \mathrm{m}^{2}$ and $27.8 \mathrm{~cm}^{3} / \mathrm{m}^{2}$, respectively. When stratified by sex, the median TPA and TPV were both higher in men $\left(685.1 \mathrm{~mm}^{2} / \mathrm{m}^{2}\right.$ and $33.0 \mathrm{~cm}^{3} / \mathrm{m}^{2}$, respectively) versus women $\left(506.3 \mathrm{~mm}^{2} / \mathrm{m}^{2}\right.$ and $22.4 \mathrm{~cm}^{3} / \mathrm{m}^{2}$, respectively) (both $P<0.001$ ) (Fig. 2a, c). In examining the entire cohort, 192 (25.1\%) patients had sarcopenia as defined by TPA, while 152 patients $(19.9 \%)$ had sarcopenia when TPV was measured. There was a trend toward decreasing TPA (correlation index: $-21, P<0.001$ ) and TPV (correlation index: $-23, P<0.001$ ) with increasing age (Fig. 2b, d). Of the $127(16.6 \%)$ patients who had a BMI $\geq 30 \mathrm{~kg} / \mathrm{m}^{2}, 27(21.3 \%)$ had sarcopenia according to TPA, and 19 patients $(15.0 \%)$ according to TPV. These patients were characterized as having sarcopenic obesity.

\section{Impact of Sarcopenia on Postoperative Complications}

Of the 763 patients who underwent pancreatic resection, 369 experienced at least one complication for an overall morbidity of $48.4 \%$. The most common complications were delayed gastric emptying (15.7\%), wound complication (13.1\%), and pancreas fistula (9.6\%). Of the 369 complications, 126 (34.1\%) were major. While sarcopenia according to TPA was not associated with the risk of morbidity (OR 1.06, $95 \%$ CI $0.77-1.47 ; P=0.72$ ), patients who suffered from sarcopenia defined by TPV were at higher risk for postoperative complications (OR 1.79, $95 \%$ CI 1.25-2.56; $P=0.002$ ) (Fig. 3a). Patients with TPVsarcopenia also had an increased risk of major complications (TPV-sarcopenia, $22.4 \%$ vs. nonsarcopenia, $15.1 \% ; P=0.03$ ) and an increased length of hospital stay (TPV-sarcopenia, 10 days vs. non-sarcopenia, 8 days; $P=0.002$ ) (Table 2). When stratifying patients into categories based on TPV quartiles, patients with the lowest TPV were noted to have the highest incidence of complications (quartile 1: $56.8 \%$ vs. quartile $2: 48.4 \%$ vs. quartile 3 : $43.2 \%$ vs. quartile $4: 45.0 \% ; P=0.04)$. On univariate analysis, BMI and type of operation were also associated with an increased risk of morbidity (all $P<0.05$ ) (Table 3 ). In a multivariate logistic regression model that accounted for competing variables, TPVsarcopenia remained independently associated with a higher risk of postoperative complication (OR 1.69, $95 \%$ CI 1.16-2.46; $P=0.006)$. Moreover, patients with sarcopenic 
obesity based on TPV had a more pronounced risk of complications compared with patients who did not have sarcopenia (TPV-sarcopenic obesity, $74.1 \%$ vs. nonsarcopenia $42.2 \%$, $P=0.003$ ) (Fig. 3b). In addition, additional analyses to explore the association of specific subtypes of complications with sarcopenia were performed; bile leak and renal complication were more common among sarcopenic patients $(P<0.05)$.

\section{Impact of TPV Sarcopenia on Long-Term Survival}

Median, 1-, 3-, and 5-year overall survival for entire cohort was 25.4 months, 76.4, 34.9, and $23.9 \%$, respectively. Several factors associated with increased risk of mortality including age (HR 1.02, $95 \%$ CI 1.01-1.03), AJCC stage II (reference stage I, HR 4.16, $95 \%$ CI 2.43-7.12), AJCC stage III (reference stage I, HR 5.43, 95 \% CI 2.59-11.4), lymph node metastasis (HR 2.29, 95 \% CI 1.73-3.02), LVI (HR 1.59, 95 \% CI 1.26-2.01), PVI (HR1.66, $95 \%$ CI 1.11-2.47), and tumor size (HR 1.02, $95 \%$ CI 1.01-1.03) (all $P<0.05$ ). The presence of TPV-sarcopenia was also associated with a worse survival and higher risk of death long-term (HR 1.72, $95 \%$ CI 1.36-2.19; P<0.001) (Fig. 4a). In a multivariable model that accounted for tumor-specific factors and age, TPV-sarcopenia remained independently associated with an increased risk of death (HR 1.46, $95 \%$ CI 1.11-1.91; $P=0.006$ ) (Table 4). To further explore any potential impact of TPVon survival, additional analyses were performed by stratifying patients into categories based on TPV quartiles. Overall 5-year survival was worst among patients in the lowest TPV quartile (quartile 1: $16.0 \%$ vs. quartile 2: $16.7 \%$ vs. quartile $3: 27.8 \%$ vs. quartile $4: 34.1 \%$; $P<0.001$ ) (Fig. $4 \mathrm{~b}$ ).

\section{Discussion}

Over the past several decades, perioperative mortality associated with pancreatic surgery has improved. ${ }^{6,38}$ In contrast, the incidence of postoperative complications remains high. ${ }^{39,40}$ Stratification of perioperative risk has traditionally focused on the presence or absence of specific medical comorbidities or the American Society of Anesthesiologists (ASA) physical status classification. ${ }^{41-43}$ The use of these metrics to assess accurately the risk of postoperative complications has been a matter of some debate. ${ }^{44,45}$ In addition, these measures typically are not helpful in risk-stratifying the long-term prognosis of cancer patients. As such, there has been an increasing interest in the use of more global metrics, such as frailty, to help stratify patients with regard to both short- and long-term outcome. While frailty can be assessed in a number of ways, sarcopenia is an objective, easily obtainable measure of the frailty syndrome. ${ }^{24,46}$ Traditionally, sarcopenia has been assessed using only a single cross-sectional measurement of the psoas muscle. ${ }^{29,31}$ The current study is important because we utilized a novel means to define sarcopenia by measuring the entire volume of the psoas muscle. In using TPV rather than TPA, we were able to assess a larger, more representative sample of lean muscle mass. In fact, we found that while TPAsarcopenia was not associated with short-term outcomes such as complications and length of stay, TPV-sarcopenia was. Specifically, patients with TPV-sarcopenia had over a 1.5-fold increased risk of perioperative morbidity and, on average, a 2-day longer hospital stay. Furthermore, TPV-sarcopenia was strongly associated with long-term prognosis. Even after controlling for other tumor-specific variables such as tumor size and lymph node status, patients with TPV-sarcopenia had around a 1.5-fold increased risk of death long-term. 
As the population of the USA ages and the median age of the surgical patient increases, accurate tools to identify patients at higher risk of a complication will become increasingly important. ${ }^{47}$ Several studies have noted that chronological age may not be a good indicator of perioperative risk. ${ }^{48-50}$ Rather than chronological age, the patient's underlying physiological status has more importance. ${ }^{51,52}$ Frailty, defined as a patient's lack of physiological reserve, may be a better indicator of perioperative risk. While several different methods have been suggested to measure frailty,${ }^{19}$ sarcopenia has been proposed as a preferred way to define frailty because it is easily obtained and quantitated. ${ }^{24,46}$ Sarcopenia is distinct from weight loss and instead specifically refers to a decrease in lean muscle mass. ${ }^{25,26}$ As demonstrated in the current study, muscle mass varied by age-with the annual decrease being slightly more notable for TPV compared with TPA ( -0.23 vs. -0.21 , $P<0.001)$. There were also variations in TPA and TPV based on differences in sex, with men having a higher mean TPA and TPV than women. These data serve to emphasize that assessment of muscle mass and derivative definitions of sarcopenia need to take into account age and sex differences (Fig. 2).

There is some heterogeneity in the published data on the impact of TPA-sarcopenia on morbidity following surgery. ${ }^{30,31,53}$ In our own previous work, we examined patients undergoing pancreatic resection for adenocarcinoma and noted that TPA-sarcopenia was not associated with morbidity or hospital stay. ${ }^{31}$ The present study confirmed these findings and expanded on our previous work. Specifically, by measuring the entire volume of the psoas rather than just a single cross-sectional image, we demonstrated in this study that sarcopenia as defined by TPV was indeed associated with perioperative outcomes. Patients with TPVsarcopenia were at a $69 \%$ increased risk of complications and also had a longer hospital stay. Of note, TPV-sarcopenia remained an independent predictor of morbidity even after adjusting for competing factors. The reason for the disparate results when examining TPAversus TPV may be due to the higher accuracy of volumetry to assess a larger sample of muscle mass, as well as the semi-automatic manner of volumetry compared with crosssectional assessment. ${ }^{54}$ In addition to TPV-sarcopenia, we noted that patients with sarcopenic obesity had a particularly high risk of postoperative complications. In fact, those patients with TPV-sarcopenic obesity had a fourfold higher risk of complications compared with obese patients without sarcopenia (Fig. 3b). Whereas previous data have suggested that patients with high BMI have a greater chance of complications, our findings highlight how patients with sarcopenic obesity are at particular risk. Through the identification of patients at high risk of perioperative complications, patients can potentially be optimized in the preoperative setting through "pre-habiliation" programs that emphasize exercise regimens and nutritional supplementation. ${ }^{55-57}$

In the current study, we also found a strong association between TPV-sarcopenia and survival. While other tumor-specific factors such as tumor size, lymph node metastasis, and the presence of PVI and LVI were independent predictors of overall survival, TPVsarcopenia remained an independent predictor of overall survival (Table 4). In fact, the overall risk of long-term mortality among patients with TPV-sarcopenia was over $46 \%$ higher than that of patients without TPV sarcopenia. Similar to our findings, Voron et al. reported on patients who underwent hepatectomy for hepatocellular carcinoma (HCC) and noted that sarcopenia was associated with long-term survival. ${ }^{27}$ In a different study, Kido et 
al. also note that sarcopenia predicted a poor prognosis among patients who underwent liver transplantation. ${ }^{58}$ Our own group, using TPA-sarcopenia, similarly noted that sarcopenia was associated with a $60 \%$ increased risk of death among patients following pancreatic surgery. Collectively, the evidence suggests that sarcopenia is a robust indicator of long-term outcome independent of tumor-specific factors.

The current study had several limitations that should be considered when interpreting the data. The retrospective nature of study did not allow us to measure other frailty parameters such as grip strength, gait speed, or exhaustion level. In addition, we examined psoas muscle mass only at one time point (i.e., within 1 month of surgery), rather than looking at changes in the psoas over a period of time. While changes in muscle mass may occur over time, a benefit of using sarcopenia and assessment of muscle mass is that, compared with weight, it is less subject to short-term fluctuation. ${ }^{59}$ In addition, we did not look at other possible parameters of frailty or sarcopenia such as serum albumin or psoas muscle density. Finally, since all patients underwent surgical resection, we were unable to assess the impact of sarcopenia on patients with pancreatic cancer who might have been too frail to be offered surgery in the first place.

In conclusion, TPV-sarcopenia was strongly associated with short- and long-term outcomes after pancreatic resection. Unlike TPA, which was not associated with short-term outcomes, TPV was a predictor of adverse perioperative events such as morbidity and a longer length of stay. In addition, TPV was associated with long-term outcome as patients in the lowest TPV quartile had the worst survival. Measuring TPV may be a more precise method than TPA to assess muscle mass, sarcopenia, and frailty. As such, the incorporation of TPV into the patient's preoperative assessment should be considered. Identification of TPV-sarcopenia may help stratify those patients at higher risk of complications and, in turn, allow for aggressive pre-habilitation in the hopes of improving outcomes.

\section{References}

1. Jemal A, Bray F, Center MM, Ferlay J, Ward E, Forman D. Global cancer statistics. CA: A Cancer Journal for Clinicians. 2011; 61:69-90. [PubMed: 21296855]

2. Winter J, Brennan M, Tang L, D’ Angelica M, DeMatteo R, Fong Y, Klimstra D, Jarnagin W, Allen P. Survival after Resection of Pancreatic Adenocarcinoma: Results from a Single Institution over Three Decades. Annals of Surgical Oncology. 2012; 19:169-75. [PubMed: 21761104]

3. Serrano P, Cleary S, Dhani N, Kim PW, Greig P, Leung K, Moulton C-A, Gallinger S, Wei A. Improved Long-Term Outcomes After Resection of Pancreatic Adenocarcinoma: A Comparison Between Two Time Periods. Annals of Surgical Oncology. 2014:1-8.

4. DeOliveira ML, Winter JM, Schafer M, Cunningham SC, Cameron JL, Yeo CJ, Clavien P-A. Assessment of complications after pancreatic surgery: a novel grading system applied to 633 patients undergoing pancreaticoduodenectomy. Ann Surg. 2006; 244:931. [PubMed: 17122618]

5. Greenblatt DY, Kelly KJ, Rajamanickam V, Wan Y, Hanson T, Rettammel R, Winslow ER, Cho CS, Weber SM. Preoperative factors predict perioperative morbidity and mortality after pancreaticoduodenectomy. Annals of surgical oncology. 2011; 18:2126-35. [PubMed: 21336514]

6. Cameron JL, Riall TS, Coleman J, Belcher KA. One thousand consecutive pancreaticoduodenectomies. Ann Surg. 2006; 244:10-5. [PubMed: 16794383]

7. Li QG, Li P, Tang D, Chen J, Wang DR. Impact of postoperative complications on long-term survival after radical resection for gastric cancer. World J Gastroenterol. 2013; 19:4060-5. [PubMed: 23840153] 
8. Löppenberg B, von Bodman C, Brock M, Roghmann F, Noldus J, Palisaar R. Effect of perioperative complications and functional outcomes on health-related quality of life after radical prostatectomy. Quality of Life Research. 2014; 23:2743-56. [PubMed: 24902939]

9. Mavros MN, de Jong M, Dogeas E, Hyder O, Pawlik TM. Impact of complications on long-term survival after resection of colorectal liver metastases. The British journal of surgery. 2013; 100:7118. [PubMed: 23364914]

10. Spolverato G, Yakoob MY, Kim Y, Alexandrescu S, Marques HP, Aldrighetti L, Clark Gamblin T, Maithel S, Pulitano C, Bauer TW, Shen F, Poultsides GA, Wallis Marsh J, Pawlik TM. Impact Of Complications On Long-Term Survival After Resection Of Intrahepatic Cholangiocarcinoma. Cancer. 2015

11. Gillis C, Li C, Lee L, Awasthi R, Augustin B, Gamsa A, Liberman AS, Stein B, Charlebois P, Feldman LS, Carli F. Prehabilitation versus rehabilitation: a randomized control trial in patients undergoing colorectal resection for cancer. Anesthesiology. 2014; 121:937-47. [PubMed: 25076007]

12. Deyle S, Banz VM, Wagner M, Becker K, Inderbitzin D, Gloor B, Candinas D. Estimation of Physiologic Ability and Surgical Stress Score Does Not Predict Immediate Outcome After Pancreatic Surgery. Pancreas. 2011; 40:723-910. 10.97/MPA.0b013e318212c02c. [PubMed: 21654545]

13. Braga M, Capretti G, Pecorelli N, Balzano G, Doglioni C, Ariotti R, Di Carlo V. A prognostic score to predict major complications after pancreaticoduodenectomy. Ann Surg. 2011; 254:702-7. discussion 7-8. [PubMed: 22042466]

14. Shah R, Velanovich V, Syed Z, Swartz A, Rubinfeld I. Limitations of Patient-Associated CoMorbidity Model in Predicting Postoperative Morbidity and Mortality in Pancreatic Operations. Journal of Gastrointestinal Surgery. 2012; 16:986-92. [PubMed: 22415858]

15. Rockwood K. Frailty and its definition: a worthy challenge. Journal of the American Geriatrics Society. 2005; 53:1069-70. [PubMed: 15935037]

16. Ferrucci L, Guralnik J, Studenski S, Fried L, Cutler G Jr, Walston J. Interventions on Frailty Working Group: Designing randomized, controlled trials aimed at preventing or delaying functional decline and disability in frail, older persons: a consensus report. J Am Geriatr Soc. 2004; 52:625-34. [PubMed: 15066083]

17. Fried LP, Tangen CM, Walston J, Newman AB, Hirsch C, Gottdiener J, Seeman T, Tracy R, Kop WJ, Burke G, McBurnie MA. Frailty in Older Adults: Evidence for a Phenotype. The Journals of Gerontology Series A: Biological Sciences and Medical Sciences. 2001; 56:M146-M57.

18. Lang P-O, Michel J-P, Zekry D. Frailty syndrome: a transitional state in a dynamic process. Gerontology. 2009; 55:539-49. [PubMed: 19346741]

19. Brown M, Sinacore DR, Binder EF, Kohrt WM. Physical and Performance Measures for the Identification of Mild to Moderate Frailty. The Journals of Gerontology Series A: Biological Sciences and Medical Sciences. 2000; 55:M350-M5.

20. Puts MTE, Lips P, Deeg DJH. Static and dynamic measures of frailty predicted decline in performance-based and self-reported physical functioning. Journal of Clinical Epidemiology. 2005; 58:1188-98. [PubMed: 16223663]

21. Verghese J, Holtzer R, Lipton RB, Wang C. Mobility Stress Test Approach to Predicting Frailty, Disability, and Mortality in High-Functioning Older Adults. Journal of the American Geriatrics Society. 2012; 60:1901-5. [PubMed: 23002714]

22. Pel-Littel RE, Schuurmans MJ, Emmelot-Vonk MH, Verhaar HJJ. Frailty: Defining and measuring of a concept. J Nutr Health Aging. 2009; 13:390-4. [PubMed: 19300888]

23. Clegg A, Rogers L, Young J. Diagnostic test accuracy of simple instruments for identifying frailty in community-dwelling older people: a systematic review. Age and Ageing. 2014

24. Cooper C, Dere W, Evans W, Kanis J, Rizzoli R, Sayer A, Sieber C, Kaufman J-M, van Kan GA, Boonen S. Frailty and sarcopenia: definitions and outcome parameters. Osteoporosis International. 2012; 23:1839-48. [PubMed: 22290243]

25. Baracos VE, Reiman T, Mourtzakis M, Gioulbasanis I, Antoun S. Body composition in patients with non-small cell lung cancer: a contemporary view of cancer cachexia with the use of computed tomography image analysis. Am J Clin Nutr. 2010; 91:1133S-7S. [PubMed: 20164322] 
26. Prado CM, Lieffers JR, McCargar LJ, Reiman T, Sawyer MB, Martin L, Baracos VE. Prevalence and clinical implications of sarcopenic obesity in patients with solid tumours of the respiratory and gastrointestinal tracts: a population-based study. Lancet Oncol. 2008; 9:629-35. [PubMed: 18539529]

27. Voron T, Tselikas L, Pietrasz D, Pigneur F, Laurent A, Compagnon P, Salloum C, Luciani A, Azoulay D. Sarcopenia Impacts on Short- and Long-term Results of Hepatectomy for Hepatocellular Carcinoma. Ann Surg. 2014

28. Meza-Junco J, Montano-Loza AJ, Baracos VE, Prado CMM, Bain VG, Beaumont C, Esfandiari N, Lieffers JR, Sawyer MB. Sarcopenia as a Prognostic Index of Nutritional Status in Concurrent Cirrhosis and Hepatocellular Carcinoma. Journal of Clinical Gastroenterology. 2013; 47:861-70. 10.1097/MCG.0b013e318293a825. [PubMed: 23751844]

29. Reisinger KW, van Vugt JL, Tegels JJ, Snijders C, Hulsewe KW, Hoofwijk AG, Stoot JH, Von Meyenfeldt MF, Beets GL, Derikx JP, Poeze M. Functional Compromise Reflected by Sarcopenia, Frailty, and Nutritional Depletion Predicts Adverse Postoperative Outcome After Colorectal Cancer Surgery. Ann Surg. 2014

30. Peng PD, van Vledder MG, Tsai S, de Jong MC, Makary M, Ng J, Edil BH, Wolfgang CL, Schulick RD, Choti MA, Kamel I, Pawlik TM. Sarcopenia negatively impacts short-term outcomes in patients undergoing hepatic resection for colorectal liver metastasis. HPB : the official journal of the International Hepato Pancreato Biliary Association. 2011; 13:439-46. [PubMed: 21689226]

31. Peng P, Hyder O, Firoozmand A, Kneuertz P, Schulick R, Huang D, Makary M, Hirose K, Edil B, Choti M, Herman J, Cameron J, Wolfgang C, Pawlik T. Impact of Sarcopenia on Outcomes Following Resection of Pancreatic Adenocarcinoma. Journal of Gastrointestinal Surgery. 2012; 16:1478-86. [PubMed: 22692586]

32. Dodson RM, Firoozmand A, Hyder O, Tacher V, Cosgrove DP, Bhagat N, Herman JM, Wolfgang CL, Geschwind JF, Kamel IR, Pawlik TM. Impact of sarcopenia on outcomes following intraarterial therapy of hepatic malignancies. Journal of Gastrointestinal Surgery. 2013; 17:2123-32. [PubMed: 24065364]

33. Prasad SR, Jhaveri KS, Saini S, Hahn PF, Halpern EF, Sumner JE. CT tumor measurement for therapeutic response assessment: comparison of unidimensional, bidimensional, and volumetric techniques initial observations. Radiology. 2002; 225:416-9. [PubMed: 12409574]

34. Mozley PD, Schwartz LH, Bendtsen C, Zhao B, Petrick N, Buckler AJ. Change in lung tumor volume as a biomarker of treatment response: a critical review of the evidence. Annals of oncology : official journal of the European Society for Medical Oncology / ESMO. 2010; 21:1751-5. [PubMed: 20332135]

35. Clavien P-A, Camargo CA Jr, Croxford R, Langer B, Levy GA, Greig PD. Definition and classification of negative outcomes in solid organ transplantation. Application in liver transplantation. Ann Surg. 1994; 220:109. [PubMed: 8053733]

36. Valero V 3rd, Amini N, Spolverato G, Weiss MJ, Hirose K, Dagher NN, Wolfgang CL, Cameron AA, Philosophe B, Kamel IR, Pawlik TM. Sarcopenia Adversely Impacts Postoperative Complications Following Resection or Transplantation in Patients with Primary Liver Tumors. Journal of Gastrointestinal Surgery. 2014

37. Edge SB, Compton CC. The American Joint Committee on Cancer: the 7th edition of the AJCC cancer staging manual and the future of TNM. Annals of Surgical Oncology. 2010; 17:1471-4. [PubMed: 20180029]

38. Hill JS, McPhee JT, Whalen GF, Sullivan ME, Warshaw AL, Tseng JF. In-hospital mortality after pancreatic resection for chronic pancreatitis: population-based estimates from the nationwide inpatient sample. Journal of the American College of Surgeons. 2009; 209:468-76. [PubMed: 19801320]

39. Seiler C, Wagner M, Bachmann T, Redaelli C, Schmied B, Uhl W, Friess H, Büchler M. Randomized clinical trial of pylorus-preserving duodenopancreatectomy versus classical Whipple resection—long term results. British journal of surgery. 2005; 92:547-56. [PubMed: 15800958]

40. Balcom JHT, Rattner DW, Warshaw AL, Chang Y, Fernandez-del Castillo C. Ten-year experience with 733 pancreatic resections: changing indications, older patients, and decreasing length of hospitalization. Arch Surg. 2001; 136:391-8. [PubMed: 11296108] 
41. Al-Homoud S, Purkayastha S, Aziz O, Smith JJ, Thompson MD, Darzi AW, Stamatakis JD, Tekkis PP. Evaluating operative risk in colorectal cancer surgery: ASA and POSSUM-based predictive models. Surgical oncology. 2004; 13:83-92. [PubMed: 15572090]

42. Bilimoria KY, Talamonti MS, Tomlinson JS, Stewart AK, Winchester DP, Ko CY, Bentrem DJ. Prognostic Score Predicting Survival After Resection of Pancreatic Neuroendocrine Tumors: Analysis of 3851 Patients. Annals of Surgery. 2008; 247:490-500. [PubMed: 18376195]

43. Braga M, Capretti G, Pecorelli N, Balzano G, Doglioni C, Ariotti R, Di Carlo V. A prognostic score to predict major complications after pancreaticoduodenectomy. Annals of Surgery. 2011; 254:702-8. [PubMed: 22042466]

44. Ansell GL, Montgomery JE. Outcome of ASA III patients undergoing day case surgery. British Journal of Anaesthesia. 2004; 92:71-4. [PubMed: 14665556]

45. Audisio RA, Ramesh H, Longo WE, Zbar AP, Pope D. Preoperative assessment of surgical risk in oncogeriatric patients. The oncologist. 2005; 10:262-8. [PubMed: 15821246]

46. Cruz-Jentoft AJ, Michel JP. Sarcopenia: A useful paradigm for physical frailty. European Geriatric Medicine. 2013; 4:102-5.

47. Control CfD, Prevention. Trends in aging-United States and worldwide. MMWR Morbidity and mortality weekly report. 2003; 52:101. [PubMed: 12645839]

48. Hatzaras I, Schmidt C, Klemanski D, Muscarella P, Melvin WS, Ellison EC, Bloomston M. Pancreatic resection in the octogenarian: a safe option for pancreatic malignancy. Journal of the American College of Surgeons. 2011; 212:373-7. [PubMed: 21227721]

49. Oliveira-Cunha M, Malde DJ, Aldouri A, Morris-Stiff G, Menon KV, Smith AM. Results of pancreatic surgery in the elderly: is age a barrier? HPB : the official journal of the International Hepato Pancreato Biliary Association. 2013; 15:24-30. [PubMed: 23216776]

50. Lahat G, Sever R, Lubezky N, Nachmany I, Gerstenhaber F, Ben-Haim M, Nakache R, Koriansky J, Klausner JM. Pancreatic cancer: surgery is a feasible therapeutic option for elderly patients. World journal of surgical oncology. 2011; 9:10. [PubMed: 21272335]

51. Buchs N, Addeo P, Bianco F, Gangemi A, Ayloo S, Giulianotti P. Outcomes of Robot-Assisted Pancreaticoduodenectomy in Patients Older Than 70 Years: A Comparative Study. World J Surg. 2010; 34:2109-14. [PubMed: 20526598]

52. Adam R, Frilling A, Elias D, Laurent C, Ramos E, Capussotti L, Poston GJ, Wicherts DA, de Haas RJ. Liver resection of colorectal metastases in elderly patients. British Journal of Surgery. 2010; 97:366-76. [PubMed: 20101645]

53. Lieffers J, Bathe O, Fassbender K, Winget M, Baracos V. Sarcopenia is associated with postoperative infection and delayed recovery from colorectal cancer resection surgery. British journal of cancer. 2012; 107:931-6. [PubMed: 22871883]

54. Gowdra Halappa V, Corona-Villalobos CP, Bonekamp S, Li Z, Reyes D, Cosgrove D, Pawlik TM, Diaz LA, Bhagat N, Eng J, Geschwind JF, Kamel IR. Neuroendocrine liver metastasis treated by using intraarterial therapy: volumetric functional imaging bio-markers of early tumor response and survival. Radiology. 2013; 266:502-13. [PubMed: 23192780]

55. Korc-Grodzicki B, Downey RJ, Shahrokni A, Kingham TP, Patel SG, Audisio RA. Surgical Considerations in Older Adults With Cancer. Journal of Clinical Oncology. 2014; 32:2647-53. [PubMed: 25071124]

56. Chow WB, Rosenthal RA, Merkow RP, Ko CY, Esnaola NF. Optimal preoperative assessment of the geriatric surgical patient: a best practices guideline from the American College of Surgeons National Surgical Quality Improvement Program and the American Geriatrics Society. Journal of the American College of Surgeons. 2012; 215:453-66. [PubMed: 22917646]

57. Braga M, Ljungqvist O, Soeters P, Fearon K, Weimann A, Bozzetti F. ESPEN guidelines on parenteral nutrition: surgery. Clinical nutrition. 2009; 28:378-86. [PubMed: 19464088]

58. Kaido T, Ogawa K, Fujimoto Y, Ogura Y, Hata K, Ito T, Tomiyama K, Yagi S, Mori A, Uemoto S. Impact of Sarcopenia on Survival in Patients Undergoing Living Donor Liver Transplantation. American Journal of Transplantation. 2013; 13:1549-56. [PubMed: 23601159]

59. Frontera WR, Hughes VA, Fielding RA, Fiatarone MA, Evans WJ, Roubenoff R. Aging of skeletal muscle: a 12-yr longitudinal study. J Appl Physiol (1985). 2000; 88:1321-6. [PubMed: 10749826] 
a
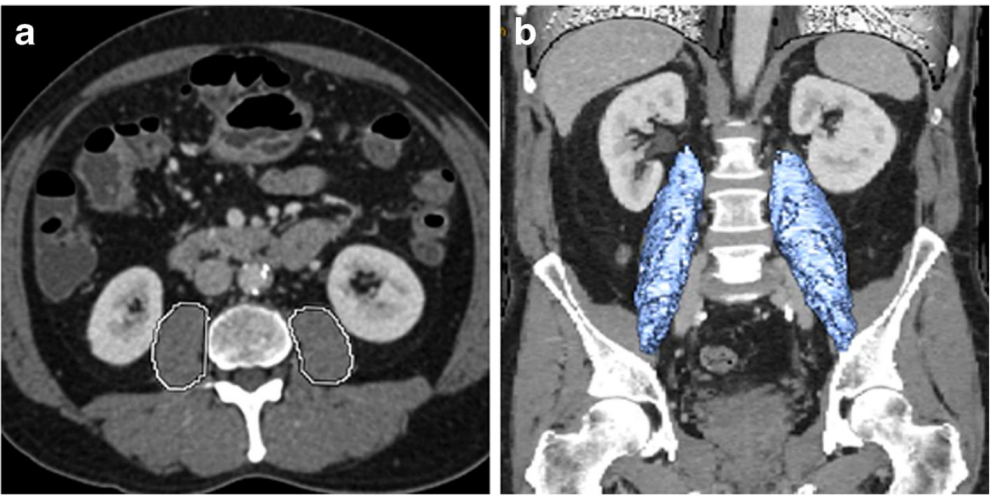

Fig. 1.

Sarcopenia measurement at the level of L3 using (a) total psoas area (TPA) and (b) total psoas volume (TPV) 
a

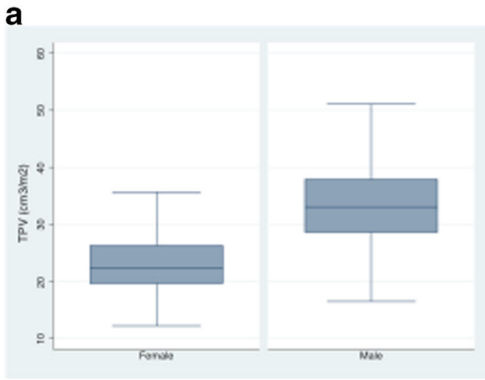

b

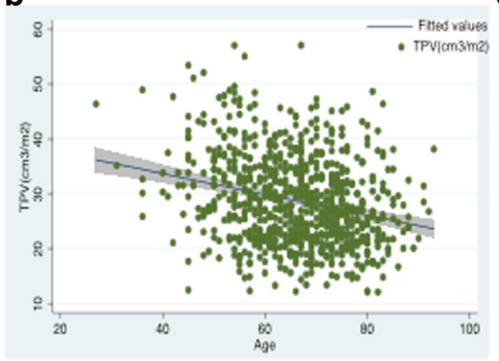

C

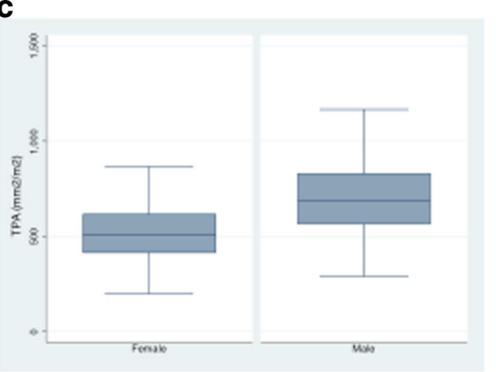

d

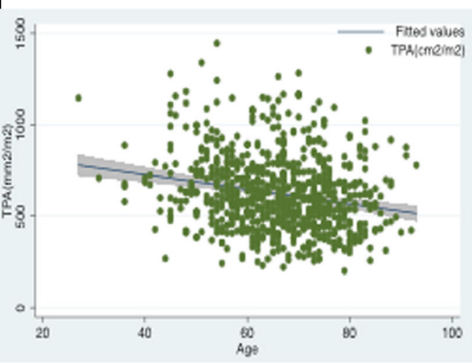

Fig. 2.

Comparison of sarcopenia distribution across gender and age: (a) distribution of TPV $\left(\mathrm{cm}^{3} / \mathrm{m}^{2}\right)$ according to gender, (b) distribution of TPV $\left(\mathrm{cm}^{3} / \mathrm{m}^{2}\right)$ according to age, (c) distribution of TPA $\left(\mathrm{mm}^{2} / \mathrm{m}^{2}\right)$ according to gender and (d) distribution of TPA $\left(\mathrm{mm}^{2} / \mathrm{m}^{2}\right)$ according to age 

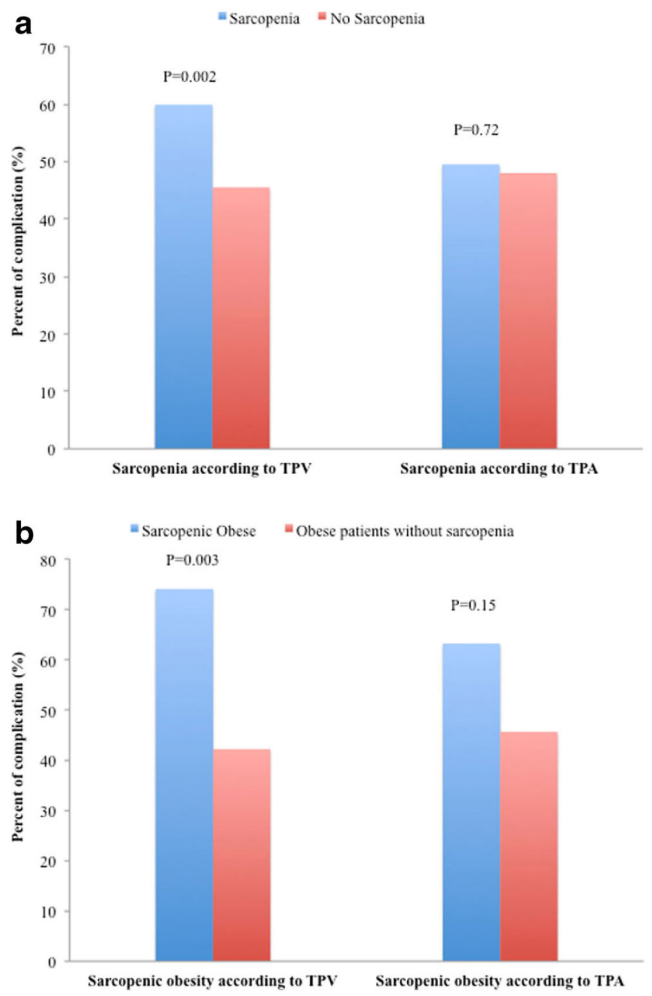

Fig. 3.

Percent of complication: (a) among sarcopenia patients vs. patients without sarcopenia and (b) among sarcopenic-obese patients vs. obese patients without sarcopenia 
a

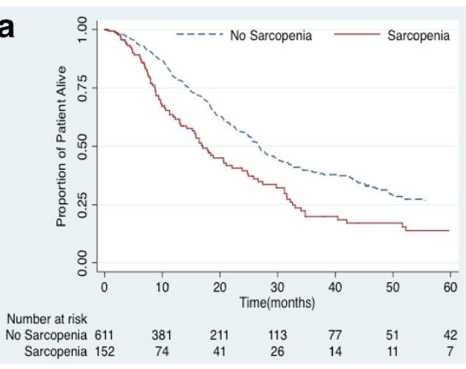

b

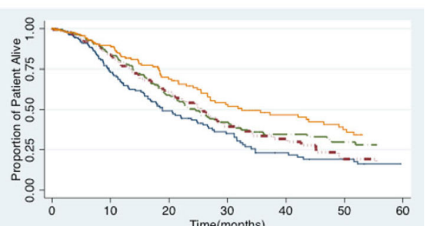

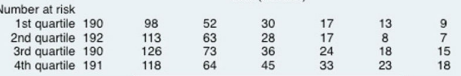

Fig. 4.

Overall survival according to total psoas volume (TPV) stratified by (a) sarcopenia patients vs. no sarcopenia patients (b) quartiles

J Gastrointest Surg. Author manuscript; available in PMC 2016 April 25 


\section{Table 1}

Demographic and clinical characteristics of patients who underwent curative resection for pancreatic adenocarcinoma

\begin{tabular}{|c|c|c|c|c|}
\hline & All patients $(n=763)$ & $\operatorname{Men}(n=418)$ & Women $(n=345)$ & $P$ value \\
\hline Age (years), median (IQR) & $67(58-74)$ & $67(58-74)$ & $66(59-74)$ & 0.73 \\
\hline Total psoas area $\left(\mathrm{mm}^{2} / \mathrm{m}^{2}\right)$, median (IQR) & $600.6(467.3-742.5)$ & $685.1(564.2-831.8)$ & $506.3(414.5-614.5)$ & $<0.001$ \\
\hline Total psoas volume $\left(\mathrm{cm}^{3} / \mathrm{m}^{2}\right)$, median (IQR) & $27.8(22.2-34.2)$ & $33.0(28.6-37.9)$ & $22.4(19.7-26.3)$ & $<0.001$ \\
\hline \multicolumn{5}{|l|}{ Race } \\
\hline White & $646(84.7)$ & $362(86.6)$ & $284(82.3)$ & 0.27 \\
\hline Black & $59(7.7)$ & $27(6.5)$ & $32(9.3)$ & \\
\hline Asian & $13(1.7)$ & $5(1.2)$ & $8(2.3)$ & \\
\hline Other & $45(5.9)$ & $24(5.7)$ & $21(6.1)$ & \\
\hline BMI, median (IQR) & $24.9(22.1-28.0)$ & $23.8(21.4-27.2)$ & $25.6(23.0-28.3)$ & $<0.001$ \\
\hline \multicolumn{5}{|l|}{ Grade of tumor } \\
\hline Well differentiated & $28(3.7)$ & $14(3.4)$ & $14(4.1)$ & 0.27 \\
\hline Moderate differentiated & $400(52.4)$ & $207(49.5)$ & $193(55.9)$ & \\
\hline Poor/undifferentiated & $310(40.6)$ & $182(43.5)$ & $128(37.1)$ & \\
\hline Other/unknown & $25(3.3)$ & $15(3.6)$ & $10(2.9)$ & \\
\hline \multicolumn{5}{|l|}{ T stage $(n=747)$} \\
\hline $\mathrm{T} 1$ & $80(10.7)$ & $39(9.5)$ & $41(12.2)$ & 0.36 \\
\hline $\mathrm{T} 2$ & $168(22.5)$ & 89 (21.6) & $79(23.6)$ & \\
\hline $\mathrm{T} 3$ & $475(63.6)$ & $268(65.0)$ & $207(61.8)$ & \\
\hline $\mathrm{T} 4$ & $24(3.2)$ & $16(3.9)$ & $8(2.4)$ & \\
\hline \multicolumn{5}{|l|}{ Stage of tumor $(n=562)$} \\
\hline Stage I & $84(15.0)$ & $42(13.6)$ & $42(16.6)$ & 0.26 \\
\hline Stage II & $458(81.5)$ & $253(81.9)$ & $205(81.0)$ & \\
\hline Stage III & $20(3.5)$ & $14(4.5)$ & $6(2.4)$ & \\
\hline Nodal metastasis & $532(70.0)$ & $304(72.7)$ & $228(66.7)$ & 0.13 \\
\hline Tumor size $(\mathrm{cm})$, median (IQR) & $3.0(2.3-4)$ & $3.0(2.4-4)$ & $2.9(2.3-3.5)$ & 0.001 \\
\hline \multicolumn{5}{|l|}{ Type of operation, $(n=755)$} \\
\hline Pancreatoduodenectomy & $583(77.2)$ & $326(78.5)$ & $257(75.6)$ & 0.47 \\
\hline Distal pancreatectomy & $139(18.4)$ & $70(16.9)$ & $69(20.3)$ & \\
\hline Total pancreatectomy & $33(4.4)$ & $19(4.6)$ & $14(4.1)$ & \\
\hline LVI $(n=872)$ & $367(56.0)$ & $203(56.6)$ & $164(55.2)$ & 0.07 \\
\hline PVI ( $n=747)$ & $646(86.5)$ & $350(85.8)$ & $296(87.3)$ & 0.19 \\
\hline
\end{tabular}

$B M I$ body mass index, $L V I$, lymphovascular invasion, $P V I$ perivascular invasion 
Table 2

Comparison of hospital stay and mortality of sarcopenia vs. non-sarcopenia patients

\begin{tabular}{|c|c|c|c|c|c|c|}
\hline & \multicolumn{3}{|c|}{ According to TPA measurement } & \multicolumn{3}{|c|}{ According to TPV measurement } \\
\hline & $\begin{array}{l}\text { Sarcopenia } \\
(n=192)\end{array}$ & $\begin{array}{l}\text { No sarcopenia } \\
(n=571)\end{array}$ & $P$ value & $\begin{array}{l}\text { Sarcopenia } \\
(n=152)\end{array}$ & $\begin{array}{l}\text { No sarcopenia } \\
(n=611)\end{array}$ & $P$ value \\
\hline Length of hospital stay, day, median (IQR) & $9(7-15)$ & $8(7-13)$ & 0.05 & $10(7-15.5)$ & $8(7-13)$ & 0.002 \\
\hline Any complication, $n(\%)$ & $95(49.5)$ & $274(48.0)$ & 0.72 & $91(59.9)$ & $278(45.5)$ & 0.002 \\
\hline Major complication, $n(\%)$ & $38(19.8)$ & $88(15.4)$ & 0.16 & $34(22.4)$ & $92(15.1)$ & 0.03 \\
\hline \multicolumn{7}{|l|}{ Postoperative mortality } \\
\hline 30 days & $1(0.5)$ & $3(0.5)$ & 1.0 & $1(0.7)$ & $3(0.5)$ & 1.0 \\
\hline 90 days & $7(3.7)$ & $10(1.8)$ & 0.12 & $6(4.0)$ & $11(1.8)$ & 0.11 \\
\hline 1 year & $56(29.2)$ & $85(14.9)$ & $<0.001$ & $45(29.6)$ & $96(15.7)$ & $<0.001$ \\
\hline 3 year & $121(63.0)$ & $187(32.8)$ & $<0.001$ & $82(54.0)$ & $226(37.0)$ & $<0.001$ \\
\hline Survival (month), median & 28.4 & 18.0 & $<0.001$ & 26.7 & 17.0 & $<0.001$ \\
\hline
\end{tabular}


Table 3

Logistic regression on the correlation between postoperative complication and sarcopenia

\begin{tabular}{|c|c|c|c|c|}
\hline & \multicolumn{2}{|c|}{ Univariable } & \multicolumn{2}{|c|}{ Multivariable $^{a}$} \\
\hline & OR $(95 \%$ CI $)$ & $P$ value & OR $(95 \%$ CI $)$ & $P$ value \\
\hline \multicolumn{5}{|l|}{ Age } \\
\hline$<60$ & Ref & & - & \\
\hline 260 & $1.15(0.87-1.51)$ & 0.33 & - & \\
\hline Male gender & $1.29(0.40-1.01)$ & 0.09 & $1.14(0.84-1.54)$ & 0.41 \\
\hline Sarcopenia according on TPA & $1.06(0.77-1.47)$ & 0.72 & - & \\
\hline Sarcopenia according on TPV & $1.79(1.25-2.56)$ & 0.002 & $1.69(1.16-2.46)$ & 0.006 \\
\hline \multicolumn{5}{|l|}{ Race } \\
\hline White & Ref & & - & \\
\hline Black & $0.93(0.55-1.59)$ & 0.80 & - & \\
\hline Asian & $0.88(0.29-2.66)$ & 0.83 & - & \\
\hline Other & $0.63(0.34-1.17)$ & 0.14 & - & \\
\hline \multicolumn{5}{|l|}{ BMI category } \\
\hline Normal weight (18.5-25) & Ref & & Ref & \\
\hline Under weight $(<18.5)$ & $0.51(0.22-1.19)$ & 0.12 & $0.54(0.22-1.31)$ & 0.17 \\
\hline Overweight/obese (>25) & $1.34(1.01-1.80)$ & 0.05 & $1.39(1.03-1.89)$ & 0.03 \\
\hline \multicolumn{5}{|l|}{ Type of operation } \\
\hline Distal pancreatectomy & Ref & & Ref & \\
\hline Pancreatoduodenectomy & $3.56(2.34-5.41)$ & $<0.001$ & $3.49(2.28-5.34)$ & $<0.001$ \\
\hline Total pancreatectomy & $6.18(2.72-14.0)$ & $<0.001$ & $6.1(2.65-14.0)$ & $<0.001$ \\
\hline
\end{tabular}

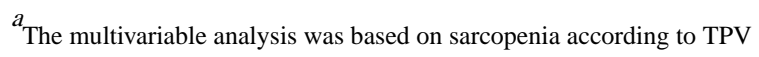




\section{Table 4}

Univariable and multivariable cox proportional hazards regression analysis of overall survival (sarcopenia according to TPV)

\begin{tabular}{|c|c|c|c|c|}
\hline & \multicolumn{2}{|c|}{ Univariable } & \multicolumn{2}{|c|}{ Multivariable for TPV } \\
\hline & HR $(95 \%$ CI $)$ & $P$ value & HR $(95 \%$ CI $)$ & $P$ value \\
\hline Age (years) & $1.02(1.01-1.03)$ & 0.003 & $1.02(1.01-1.03)$ & $<0.001$ \\
\hline Male gender & $1.05(0.85-1.30)$ & 0.64 & - & \\
\hline Sarcopenia according on TPV & $1.72(1.36-2.19)$ & $<0.001$ & $1.46(1.11-1.91)$ & 0.006 \\
\hline \multicolumn{5}{|l|}{ Race } \\
\hline White & Ref & & & \\
\hline Black & $0.92(0.62-1.36)$ & 0.67 & - & \\
\hline Asian & $0.87(0.36-2.10)$ & 0.75 & - & \\
\hline Other & $0.53(0.29-0.96)$ & 0.04 & - & \\
\hline BMI & $0.99(0.98-1.01)$ & 0.59 & - & \\
\hline \multicolumn{5}{|l|}{ Grade of tumor } \\
\hline Well differentiated & Ref & & - & \\
\hline Moderate differentiated & $1.13(0.59-2.15)$ & 0.70 & - & \\
\hline Poor/undifferentiated & $1.52(0.80-2.89)$ & 0.20 & - & \\
\hline \multicolumn{5}{|l|}{ Stage of tumor } \\
\hline Stage I & Ref & & Ref & \\
\hline Stage II & $4.16(2.43-7.12)$ & $<0.001$ & $2.67(1.43-4.98)$ & 0.002 \\
\hline Stage III & $5.43(2.59-11.41)$ & $<0.001$ & $4.10(1.82-9.21)$ & 0.001 \\
\hline Nodal metastasis & $2.29(1.73-3.02)$ & $<0.001$ & $1.44(1.00-2.07)$ & 0.05 \\
\hline Tumor size & $1.02(1.01-1.03)$ & 0.003 & $1.01(1.00-1.03)$ & $<0.001$ \\
\hline \multicolumn{5}{|l|}{ Type of operation } \\
\hline Distal pancreatectomy & Ref & & & \\
\hline Pancreatoduodenectomy & $1.27(0.94-1.72)$ & 0.12 & - & \\
\hline Total pancreatectomy & $1.60(0.92-2.78)$ & 0.09 & - & \\
\hline LVI & $1.59(1.26-2.01)$ & $<0.001$ & $1.25(0.96-1.63)$ & 0.10 \\
\hline PVI & $1.66(1.11-2.47)$ & 0.01 & $1.27(0.78-2.07)$ & 0.34 \\
\hline
\end{tabular}

$B M I$ body mass index, $L V I$ lymphovascular invasion, $P V I$ perivascular invasion 